\title{
ДОКУМЕНТОЛОГИЯ. ДОКУМЕНТОВЕДЕНИЕ
}

УдК 02+005.92

DOI: $10.33186 / 1027-3689-2021-5-61-72$

Ю. Н. Столяров

Российская государственная библиотека, Москва, Российская Федерация Научный и издательский центр «Наука» РАН, Москва, Российская Федерация

ГПНТБ России, Москва, Российская Федерация

\section{Библиотечное документоведение}

Аннотация: Статья логически продолжает и развивает тематику ранее опубликованных статей Ю. Н. Столярова «Документология: причины появления, этапы развития» и «Исходные постулаты документологии - всеобщей теории документа». В этой статье автор обосновывает необходимость разработки библиотечного документоведения как имеющего собственный предмет, собственное определение документа, собственное особенное содержание. Предметом библиотечного документоведения выступают первичный и вторичный документы, технологический, сопроводительный документы и административный документ (Record). На основе технологических документов строятся все рабочие процессы библиотеки; административные документы обеспечивают её оптимальное функционирование. Административные документы в библиотеке, как и в другом юридическом лице, разделяются на большие подклассы: плановые, учётные, отчётные, кадровые, финансовые и т.п. Важнейшие среди них - управленческие документы, обеспечивающие весь процесс руководства учреждением. В отдельный подкласс выделяется сопроводительная - обязательная составная часть и фондовой, и технологической, и административной документации. Для того чтобы развести основополагающие понятия документа в библиотечной сфере, автор предлагает: принять их специфические определения для каждого документского процесса: Документ библиотечного фонда - профильная для данной библиотеки зафиксированная и/или фиксируемая информация. Под зафиксированной информацией имеется в виду диахронный, дискретный документ, под фиксируемой (непрерывно, с постоянным обновлением) - синхронный (существующий в момент воспроизведения), континуальный (имеющий только начало) документ, а под библиотечной документацией понимать упорядоченное собрание служебных документов. Цель создания и назначение этих документов определяется спецификой тех или иных производственных библиотечных задач и функций. Автор призывает начать разработку ключевых положений и прежде всего терминов библиотечного документоведения.

Ключевые слова: документ, библиотечный документ, документ библиотечного фонда, документология, библиотечное документоведение. 


\title{
DOCUMENTOLOGY. DOCUMENT STUDIES
}

UDC $02+005.92$

DOI: $10.33186 / 1027-3689-2021-5-61-72$

\author{
Yury N. Stolyarov \\ Russian State Library, Moscow, Russian Federation Science and Publishing \\ Center "Nauka" of Russian Academy of Sciences. Moscow, Russian Federation \\ Russian National Public Library for Science and Technology, \\ Moscow, Russian Federation
}

\section{Library documentology}

\begin{abstract}
The article is a follow-up of the previous publications by $\mathrm{Yu}$. N. Stolyarov "Documentology: The backgrould and development" and "The basic postulates of documentology as the general theory of documents". The author substantiates the need for developing the library documentology as an individual discipline with its specific subject, specific document definition, and specific content. The subjects of library document studies are the primary and secondary document; technological document; accompanying document; and administrative document (record). The library workflows are based on procedural documents that form the class of administrative documents that ensure the optimal functioning of the library. Administrative documents in the library, as in other legal entities, are grouped into large subclasses: planning, accounting, reporting, personnel, financial documents, etc. Among them, the managerial documents are mostly important as they are to support the entire management process. Beside these subclasses, the accompanying documentation forms the subclass that makes an essential part of the collection, namely technological, and administrative documentation. To separate the fundamental library concepts of the document, the author proposes to adopt a specific definition for each document process. The library collection document is information specific for the library that is fixed or to be fixed. Fixed information refers to the diachronous, discrete documents, information to be fixed (continuously and to be continuously updated) refers to synchronous (existing at the time of retrieval), continuous (having only the beginning) document. The author defines library documentation as the systematized collection of internal documents. The tasks and purpose of these documents are determined by the specific of library technological tasks and functions. The author insists on developing the key provisions and, above all, the terms of library documentology.
\end{abstract}


Keywords: document, library document, library collection document, documentology, library documentology.

Ранее журнал опубликовал статьи «Документология: причины появления, этапы развития» [1] и «Исходные постулаты документологии - всеобщей теории документа» [2]. Изложенные в них фундаментальные основы можно развить применительно к библиотековедению.

Один из постулатов документологии гласит: поскольку каждая социальная система располагает собственной номенклатурой документов, постольку она нуждается в собственном документоведении (управленческом, архивном, библиотечном, банковском, криминалистическом и т.д.). Соответственно каждому требуется собственное определение документа, состоящее из двух частей - общей (абстрактной) и факультативной, конкретизирующей первую применительно к своей специфике. В данном случае важно подчеркнуть, что объективно существует библиотечный документ и важно его выявить, описать, дать собственное определение, разработать его теорию.

Библиотековедению и родственным ему дисциплинам предстоит осознать этот факт и следующий из него вывод о необходимости разработать собственное документоведение - библиотечное. Библиотечное документоведение имеет собственный предмет, собственное определение документа, собственное содержание.

\section{Предмет библиотечного документоведения}

По первому закону документологии библиотечное документоведение имеет такое же право на существование, как документоведение административное, архивное, криминалистическое или иное. Из своего шестидесятилетнего трудового стажа я (с единомышленниками) добрых полвека потратил на то, чтобы отстоять правомерность введения в библиотечную практику понятия документ как системного фондообразующего элемента.

Заслуга в утверждении базового для области библиографии понятия вторичный документ принадлежит прежде всего Олегу Павловичу Коршунову (9 февр. 1926 - 27 окт. 2013). Термин документ нехотя были вынуждены принять и книговеды: ГОСТ 7.60-2003 «Издания. Ос- 
новные виды. Термины и определения» утвердил представление об издании как виде документа. Обновлённый аналогичный ГОСТ, вступивший в силу в декабре 2020 г., продолжил и усилил эту традицию. Определение документа приведено в нём по ГОСТу Р 7.0.8-2013 «Делопроизводство и архивное дело», статья 7. Уточнена дефиниция электронного издания документа, которое тоже стало рассматриваться как электронный документ (группа электронных документов), - ГОСТ Р 7.0.60-2020. Издания. Основные виды. Термины и определения. Москва : Стандартинформ, 2020. - 42 с.

За прошедшие с тех пор десятилетия можно было бы разработать и другие виды документов, тоже абсолютно необходимые библиотеке и обеспечивающие её функционирование как системы, но напрямую не относящихся к фондообразующим элементам. Об этих видах все хорошо знают, но не осознают, что они вписаны в единый комплекс, и соответственно библиотечное документоведение остаётся в библиотековедении понятием-невидимкой.

Речь идёт ещё о документах технологических, на основе которых построены буквально все рабочие процессы библиотеки. Их стандартизации уделяется большое внимание, но эта работа проводится вне осмысления того, что и она является частью всего библиотечного документного комплекса.

Кроме того, существует класс документов, тоже обеспечивающих оптимальное функционирование библиотеки, - административные. Библиотека как хозяйствующий субъект находится в правовом поле Административного кодекса Российской Федерации. Административные документы в библиотеке, как и в другом юридическом лице, разделяются на большие подклассы: плановые, учётные, отчётные, кадровые, финансовые и т.п.

Одни из важнейших среди них - управленческие документы, обеспечивающие весь процесс руководства учреждением. Между тем относительно полно разработанное управленческое документоведение остаётся вне поля зрения библиотековедов. Исключение составляет лишь диссертация Анны Сергеевны Румянцевой «Система библиотечной документации как ресурс управления библиотекой» (2015) [3]. Как предмет преподавания и в высшей, и в средней библиотечной школе 
его обходят стороной, хотя документистом сегодня, в правовом государстве, обязан быть каждый.

Управленческим документоведением обязан владеть, хотя бы на ознакомительном уровне, каждый библиотечный управленец, каждый рядовой сотрудник, однако документоведческая тематика напрочь отсутствует и в программах дополнительной квалификации руководителей библиотечного дела.

Помимо названных подклассов документов в отдельный подкласс можно выделить сопроводительную документацию. Она является обязательной составной частью и фондовой, и технологической, и административной документации и заслуживает того, чтобы выделить в ней общие положения и ознакомить с ними всех библиотекарей.

В предельно сжатом виде предмет библиотечного документоведения можно представить в форме таблицы:

\begin{tabular}{|c|c|c|c|c|}
\hline \multirow[b]{3}{*}{$\begin{array}{c}\text { Класс } \\
\text { документов }\end{array}$} & \multicolumn{4}{|c|}{ Вид документов } \\
\hline & \multirow[b]{2}{*}{ 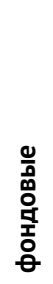 } & \multirow[b]{2}{*}{ 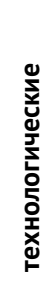 } & \multicolumn{2}{|c|}{ административные } \\
\hline & & & 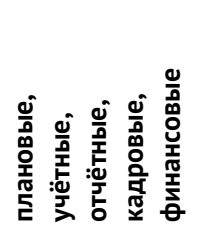 & 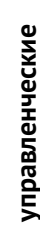 \\
\hline $\begin{array}{l}\text { Основные } \\
\text { исходные } \\
\text { (первичные и } \\
\text { вторичные) }\end{array}$ & + & + & + & + \\
\hline $\begin{array}{l}\text { Дополнительные } \\
\text { (производные, } \\
\text { вторичные, } \\
\text { модельные) }\end{array}$ & + & + & + & + \\
\hline $\begin{array}{l}\text { Сопроводитель- } \\
\text { ные }\end{array}$ & + & + & + & + \\
\hline
\end{tabular}

Первостепенная задача теории библиотечного документа - начать разработку ключевых терминов в этой области. Например, за рубежом для класса управленческих документов принят термин record (буквально означающий «запись»), отделяемый от более общего термина document. 
Было бы полезно и нам предложить собственный термин для каждого класса и вида документов, определить каждое понятие - это резко уменьшило бы количество недоразумений, возникающих на терминологической почве. К сожалению, вместо этого российские разработчики стандартов лукавят, сознательно вводя в заблуждение тех, кто привык доверять заявлениям о том, что российская терминология согласована с международной. Продемонстрирую этот тезис анализом базовой терминологической части ГОСТа Р ИСО 15489-1-2007 СИБИД. Управление документами. Общие требования [4].

В преамбуле утверждается, что ГОСТ подготовлен на основе соответствующего аутентичного перевода международного стандарта ИСО 15489-1:2001 «Информация и документация. Управление записями. Общие положения» (ISO 15489-1:2001 "Information and documentation Records management - General"). Но следом внесено «скромное» уточнение: наименование русскоязычного стандарта изменено относительно наименования аутентичного перевода. Вот так аутентичность!

Оказывается, исходным, ключевым международным термином record разрешается пренебречь ради его нивелирования, приведения в соответствие со слаборазвитой российской документологической терминологией. Такое «разрешение» освящено авторитетом ГОСТа Р 1.52004 «Стандартизация в Российской Федерации. Стандарты национальные Российской Федерации. Правила построения, изложения, оформления и обозначения» (п. 3.5).

Принципиальное (не чисто лексическое) различие состоит в том, что record можно переводить только как управленческий документ, или административный документ, распространять на него содержание всеобщего термина документ непозволительно. В библиотечном документоведении, за вычетом документов библиотечного фонда, предметом рассмотрения являются классы именно административных и технологических документов. Хорошо бы найти для них такой же однословный термин, который в международной практике именуется record в отличие от более общего document.

Рассматриваемый ГОСТ Р ИСО (указание на его соответствие ИСО, как мы только что убедились, лукаво) примечателен ещё в одном отношении, исключительно важном для библиотечного фондоведения и 
библиотековедения в целом. Оказывается, для собственного вида документа (именуемого в данном случае record) вполне естественно иметь и собственное определение: управленческий «документ (record): Зафиксированная на материальном носителе идентифицируемая информация, созданная, полученная и сохраняемая организацией или физическим лицом в качестве доказательства при подтверждении правовых обязательств или деловой деятельности». Из международного определения документа здесь взята общая часть: указание на то, что документ есть зафиксированная на материальном носителе идентифицируемая (т.е. существующая в знаковой форме) информация. Вторая часть - что эта информация способна быть единицей того или другого семантического процесса - здесь конкретизирована: сделан акцент на главном сущностном отличительном свойстве управленческого документа - служить доказательством при подтверждении правовых обязательств или деловой деятельности учреждения.

Определение документа, взятое из одного стандарта системы СИБИД, расходится с другим определением документа из той же системы - ГОСТ Р 7.0.8-2013 «Делопроизводство и архивное дело. Термины и определения»: «Документ: Зафиксированная на носителе информация с реквизитами, позволяющими её идентифицировать» [5]. В этом определении акцент сделан на наличии реквизитов, а правовое значение документа полностью проигнорировано.

Из приведённого факта методологически следуют принципиальная обоснованность и возможность разрабатывать и принимать собственные определения документа во всех необходимых случаях. Но именно этого и боятся современные библиотековеды и библиографоведы, отказывающиеся вводить термин документ со специфическими определениями в соответствующие терминологические ГОСТы. Драматична судьба этого термина в Федеральном законе «О библиотечном деле»: вместо того, чтобы раз от разу совершенствовать его определение, в одном из вариантов закона от него попросту отказались!

Чтобы закончить разговор о рассматриваемом ГОСТе, замечу: в 2016 г. ISO приняла новую версию стандарта - ISO 15489:20165, на её базе подготовлен новый российский ГОСТ Р ИСО 15489-1-2019 «СИБИД. Информация и документация. Управление документами. Часть 1. Понятия и принципы». Он введён в действие с 1 янв. 2020 г. и 
заменил собой первый вариант стандарта ГОСТ Р ИСО 15489-1-2007. Новый российский стандарт настолько же идентичен международному ISO 15489-1:2016, насколько был идентичен своему аналогу и прежний, т.е. свойственные ему огрехи остались.

Начиная с 2005 г. в России практически ежегодно утверждались стандарты в сфере управления информацией и документами, разработанные на базе стандартов ИСО:

ГOCT P 54989-2012/ISO/TR18492:2005 «Обеспечение долговременной сохранности электронных документов»;

ГОСТ Р ИСО 23081-1-2008 «Процессы управления документами. Метаданные для документов»;

ГОСТ Р ИСО 22310-2009 «Информация и документация. Руководство для разработчиков стандартов, устанавливающих требования к управлению документами»;

ГОСТ P 54471-2011/ISO/TR15801:2009 «Системы электронного документооборота. Управление документацией. Информация, сохраняемая в электронном виде. Рекомендации по обеспечению достоверности и надёжности»;

ГОСТ Р 53898-2010 «Системы электронного документооборота. Взаимодействие систем управления документами. Требования к электронному сообщению»;

ГОСТ Р ИСО 15836-2011 «Информация и документация. Набор элементов метаданных Dublin Core»;

ГОСТ Р 13008-2015 «Информация и документация. Процессы конвертации и миграции электронных документов»;

ГOCT P 57551-2017/ISO/TR18128:2014 «Информация и документация. Оценка рисков для документных процессов и систем».

Кроме того, в 2015 г. был принят первый из серии стандартов ИСО на системы управления документами - ГОСТ Р ИСО 30300-2015 «Информация и документация. Системы управления документами. Основные положения и словарь», а в 2018 г. - ГОСТ Р 7.0.101-2018/ИСО 30301:2011 «Информация и документация. Системы управления документами. Требования». 
В 2015 г. принят третий международный стандарт ИСО 30302:2015 (название на русском языке: «Информация и документация. Системы управления документами. Руководство по внедрению»), аналог которого пока в России отсутствует. Всего ИСО планирует разработать пять стандартов серии «Системы управления документами». Все они входят в состав стандартов на системы менеджмента и совместимы с ними (см. [6]). И при переводе на русский язык термина record по-прежнему будет использоваться его «русский эквивалент» - слово документ...

Из первого закона документологии вытекает, что каждая сфера деятельности нуждается в собственном документоведении и ей требуется собственное определение документа. Библиотечный документ не то же, что документ библиотечного фонда, а технологический документ - не то же, что документ управленческий или сопроводительный. У нас же сейчас ситуация противоестественная: библиотековедение, библиография, книговедение, игнорируя положение об относительности понятия документ, механически переносят в свою сферу определение документа из делопроизводственной сферы, добровольно отказываясь от углублённой разработки собственной профессиональной терминологии.

Для того чтобы развести основополагающие понятия документа в библиотечной сфере, предлагаю следующие определения.

Документ библиотечного фонда - профильная для данной библиотеки зафиксированная и/или фиксируемая информащия. Под зафиксированной информацией имеется в виду документ, во-первых, диахронный (т.е. момент обращения к которому, после того как он создан, не зависит от времени его создания), а во-вторых, дискретный, т.е. имеющий начало и конец, неизменное содержание. Под фиксируемой информацией понимается документ, во-первых, существующий только синхронно с его считыванием, восприятием. Во-вторых, под этот термин подпадает документ континуальный, т.е. имеющий начало, но постоянно (непрерывно, периодически или спорадически пополняемый/обновляемый).

Главное в этом определении - соответствие документа профилю библиотечного фонда, что требует самой тщательной проработки поня- 
тия профиль библиотечного фонда. В первом приближении это выполнено в ГОСТе Р 7.0.102-2018 «Профиль комплектования фондов научных библиотек. Структура. Индикаторы комплектования». Профиль комплектования библиотечного фонда определён в нём как служебный документ, «в котором зафиксирована модель или комбинация моделей, регламентирующая основные направления и особенности комплектования системы фондов библиотеки или информационного центра и определяющая тематику, виды и экземплярность документов, включаемых в состав библиотечного фонда» [7].

Дальнейшее совершенствование этого определения видится в том, чтобы отказаться от слова «комплектование», поскольку профиль относится ко всему фонду, а не только к одному из процессов его функционирования. Кроме того, определение профиля фонда надо распространить на библиотеки всех типов.

Библиотечная документация - упорядоченное собрание служебных документов. Цель создания и назначение этих документов определяются спецификой тех или иных производственных библиотечных задач и функций. Как упоминалось в начале статьи, опыт осмысления этого феномена, по счастью, содержится в кандидатской диссертации А. С. Румянцевой [3] и серии её публикаций по этой теме.

К сожалению, вместо того, чтобы усиленно разрабатывать профильную документологическую проблематику, библиотековеды, едваедва внедрив термины документ и документный ресурс, начали усиленно от них отказываться в пользу так называемого информационного ресурса или даже просто ресурса - без уточнения предиката, хотя ресурсы, как известно, бывают разные: человеческие, финансовые, материальные и многие иные. Публикуемые в профессиональной прессе возражения против этого бездумно внедряемого термина попросту беззастенчиво игнорируются.

Не только документология в целом, но и библиотечное документоведение находятся на начальной стадии развития и нуждаются в интенсивном исследовании своих научных основ. Надо осознать это обстоятельство и приняться за его исправление. Здесь представлены самые первые шаги в этом направлении. 


\section{СПИСОК ИСТОЧНИКОВ}

1. Столяров Ю. Н. Документология: причины появления, этапы развития / Ю. Н. Столяров // Науч. и техн. б-ки. - 2021. - № 1. - С. 15-26.

2. Столяров Ю. Н. Исходные постулаты документологии - всеобщей теории документа / Ю. Н. Столяров // Там же. - № 2. - С. 15-40.

3. Румянцева А. С. Система библиотечной документации как ресурс управления библиотекой : дис. ... канд. пед. наук : 05.25 .03 / Моск. гос. ин-т культуры. - Орёл, 2015. 341 л. : ил.

4. ГОСт Р ИСО 15489-1-2007 СИБИД. Управление документами. Общие требования. - Режим доступа: http://docs.cntd.ru/document/gost-r-iso-15489-1-2007-sibid.

5. гоСт P 7.0.8.-2013 Делопроизводство и архивное дело. Термины и определения. Режим доступа: https://ecm-journal.ru/card.aspx?ContentID=5146136.

6. Янковая В. Новый стандарт по управлению документами: ГОСТ Р ИСО 15489-12019 // Делопроизводство и документооборот на предприятии. - 2019. - Сентябрь. C. 3-11. - Режим доступа: http://www.delo-press.ru/articles.php?n=31287.

7. ГОСт P 7.0.102-2018 Профиль комплектования фондов научных библиотек. Структура. Индикаторы комплектования. - Режим доступа: http://docs.cntd.ru/document/1200159408. П. 3.6.

\section{REFERENCES}

1. Stolyarov Yu. N. Dokumentologiya: prichiny poyavleniya, etapy razvitiya / Yu. N. Stolyarov // Nauch. i tehn. b-ki. - 2021. - № 1. - S. 15-26.

2. Stolyarov Yu. N. Ishodnye postulaty dokumentologii - vseobshchey teorii dokumenta / Yu. N. Stolyarov // Tam zhe. - № 2. - S. 15-40.

3. Rumyantseva A. S. Sistema bibliotechnoy dokumentatsii kak resurs upravleniya bibliotekoy : dis. ... kand. ped. nauk : 05.25 .03 / Mosk. gos. in-t kultury. - Orel, 2015. - 341 l. : il.

4. GOST R ISO 15489-1-2007 SIBID. Upravlenie dokumentami. Obshchie trebovaniya. - URL: http://docs.cntd.ru/document/gost-r-iso-15489-1-2007-sibid.

5. GOST R 7.0.8.2013 Deloproizvodstvo i arhivnoe delo. Terminy i opredeleniya. URL: https://ecm-journal.ru/card.aspx?ContentID=5146136.

6. Yankovaya V. Novyy standart po upravleniyu dokumentami: GOST R ISO 15489-12019 // Deloproizvodstvo i dokumentooborot na predpriyatii. - 2019. - Sentyabr. S. 3-11. - URL: http://www.delo-press.ru/articles.php?n=31287. 
7. GOST R 7.0.102-2018 Profil komplektovaniya fondov nauchnyh bibliotek. Struktura. Indikatory komplektovaniya. - URL: http://docs.cntd.ru/document/1200159408. P. 3.6.

\section{Информация об авторе / Information about the author}

Столяров Юрий Николаевич - доктор пед. наук, проф., главный научный сотрудник Российской государственной библиотеки и Научного и издательского центра «Наука» РАН, главный научный сотрудник ГПНТБ России, заслуженный работник культуры РФ, Москва, Российская Федерация

yn100@narod.ru
Yury N. Stolyarov - Dr. Sc. (Pedagogy), Prof., Chief Researcher, Science and Publishing Center "Nauka" of Russian Academy of Sciences; Chief Researcher, Russian State Library; Chief Researcher, Russian National Public Library for Science and Technology, Moscow, Russian Federation

yn100@narod.ru 